\title{
Brownfield (re)development: new perspectives for Zaton in Irkutsk
}

\author{
Barbara Engel $^{1}$, Valery Kozlov ${ }^{2, *}$ \\ ${ }^{1}$ International Urbanism Department, Germany \\ ${ }^{2}$ National Research Irkutsk State Technical University, 664074, Lermontova str., 83, Irkutsk, Russia
}

\begin{abstract}
Re)development of Brownfields is nowadays a challenging task for growing cities since they represent valuable ressources for their future development - such as in Irkutsk. Therefor the development of peninsula Zaton is a responsibly issue not only concerning the sustainable development of the territory itself, but as well of the whole city. The article explains the tasks and problems of the 19th session of Baikal Winteruniversity and reviews the results.
\end{abstract}

\section{Introduction}

The conversion of former industrial or military territories is an challenging issue in urban planning worldwide - such as in Irkutsk. In the urban age, people are increasingly moving to the cities - the population in urban agglomerations is growing. Cities are urgently looking for space, particularly to satisfy the need for housing, but also to be able to offer commercial spaces. At the same time, they are trying to prevent additional land usage, i.e. outwards expansion of the city. Former industrial areas offer valuable cultural, economic, and spatial potential for inner development. Projects all over the world show the succesful practise to convert areas of former industrial or military use into mixed districts and vital neighboordhods with the offer of various usages such as offices, cultural assets and leisure activities.

While fertile land has to make way for new buildings, more and more brownfields in the cities and communities remain unused. Land use and overdevelopment are one among the most pressing environmental problems at present. Other consequences are higher costs for the community and a loss of urban quality of living. The reactivation of land reserves in the inner cities plays a key role in this process. Growing interest of real estate users to work and live within urban locations also gives rise to hope. Meanwhile, numerous inner city quarters have been reporting population growths again and the number of residents in many rural areas has been declining. Urban brownfields meanwhile appear in a new light: as a chance of making the quarters more interesting, worth living and more attractive for new redevelopment concepts. Inner city locations are more sustainable for construction of projects than projects on rural land, not only in terms of demographic trends. The reactivation of these brownfields is not only facilitated by overall improvement of conditions but also because by increasing know-how overcome development hindrances is available.

\footnotetext{
*Corresponding author: kozlov@isru.edu
} 


\section{Materials and Methods}

There are numerous advantages of brownfield redevelopement compared to building new areas on the edge of town, such as the better site quality (centrality, public transport, urban environment, closer location to business partners), lower risk of vacancy due to a broad utilization spectrum, especially when mixed use applied, lower construction cost thanks to available infrastructure, and lower allocated costs because of the utilization of public infrastructure, savings on ecological compensation measures, marketing advantage and longer life cycle of buildings with special flair. However, there are disadvantages and risks e.g. contamination and its handling, the difficulty of engaging different stakeholders, marketing troubles caused by "brownfield" image, sometimes costly or restrictive regulations, e.g. monument protection for existing buildings.

Irkutsk, a city in Eastern Siberia with a population of about 623,000, located 43 miles from Lake Baikal, is a commercial and cultural center of the region. Irkutsk is the administrative centre of Irkutsk Oblast and one of the largest cities in Siberia. Irkutsk is a growing, a scientific and educational city where more than one hundred thousand students study. Also Irkutsk ascribed to the Historical city of Russia and the historic center declared a provisional list of UNESCO World Heritage. [4] Irkutsk located on the watersides of the river Angara and so-called «the gate of Baikal».

After 25 years since dissolution of the Sowjet system, Irkutsk is still a city in transition and therefor undergoing a period of significant changes in its socio-economic and politicaladministrative reorganization, which influences the spatial structure of the city. Bustling construction activities can be observed in the city center as well as on the outskirts. As a result, particularly shops, gastronomic, and service facilities have established themselves in the city center over the last ten years. Buildings as well as entire structures of quarters are currently being rebuilt or altered. The backlog of usage for the former Soviet city is enormous and it can be expected that the requirement for further functional enhancements will persist. The growing motorization primarily, but not exclusively, presents an increasing strain on the city center through transit traffic and greater parking pressure. Noise and exhaust emissions reduce the quality of living and stay, the green courtyards around the wooden houses are blocked by parked cars. Public transportation, consisting of trams, trolley buses, buses, and minibuses, is too ineffective and uncomfortable to provide relief.

Irkutsk is known as the place of exile for leaders of the Decembrist revolt of 1826, which brought European, and particularly French culture - language, music, literature, lifestyle - to the Eastern Siberian city. In common parlance, the city is referred to as the Paris of Siberia. It boasts numerous decorative wooden houses from the 18th and 19th centuries, more than 400 of which are listed buildings. [3] But the city also has an industrial past. In mid 18th century the first small craft producer and small factory, for example, the first brickyard were opened. In 19 th century around 30 mall factories were in use, all located along the river Ushakovka. In the early 20th century the first large factory was built along the Trans-Siberian railway. Since the 1930s industrial construction of the city grew: Mechanical engineering plants, the air plant, brick and concrete plants, tea fabric, plants of food industry were built. In mid 20th century heavy engineering factories, aircraft factory and other large factories were established.

With the end of the Soviet Union, many production plants were closed. In the 1990es, privatization disrupted the industrial lines and cycles in the remaining facilities. All that time the sites were divided up more and more among new owners that started to use them for their own purposes. Industrial production facilities were closing, creating vacant areas waiting for reuse, but in times of uncertain economic prevision, the risk of possible ground pollution is a drawback for their redevelopment. The city owns many former industrial areas which now mainly lie dormant or are used inefficiently, waiting for reuse. Today, these harbor valuable 
resources for future developments. Concepts for a coordinated, social, commercial, and ecological development of the conversion areas in Irkutsk which also take long-term horizons into consideration are still lacking. They frequently display heterogenous usage areas and fragmented constructional structures. Several of these boast special location advantages, since they lie by the water. These include the Zaton peninsula with an area of about 75 hectares, situated by the banks of the Irkut and Angara rivers. A territory with a port and former industrial and storage facilities.

Due to the pressure for growth, it is high time to tackle the planning and development of this area. With its prominent position on the water and near the city center, a new district could be created here in the future with diverse uses, living, service, and recreational facilities - a new address with a special flair that strengthens the profile of the city as a cultural and economic center and makes it attractive as a place of residence. The 19th Baikal Winter University wanted to develop planning strategies and urban concepts for this. Which role can Zaton take on regarding the context of the city as a whole? How can the area be better connected to the surroundings spatially and functionally? The location on the water opens up the possibility of creating attractive recreational facilities and living quarters by the river. As part of the workshop, visions and holistic strategies as well as suggestions for interventions for individually selected locations should be compiled.

Methode Teams. The session of Baikal Winteruniversity in year 2018 brought once more young experts from different countries and various disciplines together. Die Teams wurden so zusammengestellt, dass Personen mit unterschiedlichen Professionen und Erfahrungen zusammenarbeiteten. In jeder Gruppe war mindestens ein erfahrener Student aus dem Bereich Architektur / Städtebau vertreten.

Betreuung. Der Workshop begann mit der Erläuterung der Aufgabenstellung und des Programms und der anschließenden Ortsbegehung. Zu Beginn der ersten Woche gab es einführende Vorträge von lokalen Experten - in der zweiten Woche wurden best-practiceProjekte von internationalen Experten präsentiert. Vier Assistenten waren für die kontinuierliche fachliche Betreuung zuständig und ansprechbar für Fragen. Darüber hinaus gab es zwei Zwischenpräsentationen, bei denen Planer aus Irkutsk und Experten aus anderen Städten Hinweise für die weitere Arbeit gaben. Im Anschluss an die Präsentationsveranstaltungen gab es im Anschluss eine allgemeine Reflektionsrunde sowie sich daran anschließende individuelle Besprechungen mit den Gruppen, um die Kommentare einzuordnen und die weitere Vorgehensweise zu besprechen.

Präsentation und Bewertung. Bei der Abschlusspräsentation wurden die Projekte von den Teams öffentlich vorgestellt und diskutiert. Im Anschluss daran fand - unter Ausschluss der Teams - eine Jurysitzung statt, in der die Arbeiten noch einmal intensive gewürdigt und bewertet wurden. Zunächst wurde von jeweils einem Fachkollegen eine Arbeit mit ihren Vorzügen und Schwächen eingeschätzt - mit Ergänzungen durch die weiteren Experten. Anschließend fanden Wertungsrundgänge statt - nacheinander wurden Arbeiten durch Abstimmung ausgeschlossen. Im Ergebnis wurden zwei erste Plätze vergeben.

Ergebnisse. The outcomes are valuable contributions to the ongoing debate of perspectives of this precious peninsula. All projects are looking carefully at the exisitng structures, in order to enchance the genius loci. All projects are presenting new mobility concepts which are very much needed. All projects present such concepts that aimed not for monofunctional but mixed and vital districts. All projects present strong identites for the today neglegted area. In common all authors very much understand that urban design is not only about defining programms and put buildings on a site, but more over a strategy how to integrate different stakeholders and implement the manifold ideas by developing a "road map" in order to guide a longlasting planing process.

However, the four projects differ - in intrepretation of the site as well as of the whole city of Irkutsk as well in the proposed masterplans, and offer by that a wide range of potentials for 
future development.

The Wooden Openinsula uses the wood as key issue and impulse for the concept and develops a new strong brand for the peninsula The project is based on the existing, howewer hidden treasures - such as the wood, metal and ship industry but a well as social network of the community. Aim is to enhance culture and identity by emphasizing cultural heritage and combining local production and education. In a manifold manner the project presents wood as important heritage and identity of Irkutsk. The proposed building structures shape the Island and frame an urban forest that is used for production as well as for educational and leisure facilities. However grade of density is questionable for this very valuable territory and balance between built frame and open territory is not satisfying. But the urban forest could turn into a unique asset - economicall, ecologically and socially. The urban forests depolloute the ground and contain various functions such as craftsmen ateliers or a botanical garden where endagered flowers of the Baikal region could grow.



Fig. 1. Wooden Openinsula.

Intrazaton estimates Zaton with its exisiting working places and inhabitants not as a brownfield. Aim and strategy at the same time is to improve the existing features, to create synergies and by implementing specifc new funcitons and buildingngs to developing one wholistic new district: the industrial campus. The authors explain convincingly what a industrial campus could be in the 21 st century and how it would contribute to the city: a vibrant body with different mosacis of education and production, stimulatig joint ventures between industries, companies, entrepeneurs, workers, researchers and others. Structural concepts concerning mobility and transport, zoning are as convining as the very detailed worked out strategy of involvement of the different stakeholders which is an important requirement for realizing the concept at all. Unfortunately the masterplan does not reflect the conceptional approach and lacks spatial orientation and clear organisation of neighborhoods. 
Taking very specificly the existing values into account, built as well natural elements, the authors show how to take care of the limited ressources in Irkutsk. The industrial campus by that shows a very sustainable approach in urban planning.



Fig.2. Intrazaton.

The Village of Creativity points out that the future of cities is very much depending on the ability to attract the so called creative class. [1] Irkutsk, as a cultural center in East Siberia, owns already many cultural and art facilities that is reason for the authors to strenghten this feature. The Village of Creativity presents certain features concerning art, education and production. Part of the master plan is the implementation of a new concert hall as anchor nice to have, but looking at many problems and huge efforts which would be related to such big investment it should not be seen as key project to get the development of the district stimulated. The project offers attractive alternatives to the private car - so much needed in Irkutsk - that includes collective parking facilities, enhancement of the public transport network with new bus lines, a new train connection, a cable car and more. The cable car would even be more than a mobility system but as well an asset for the district and the city. 

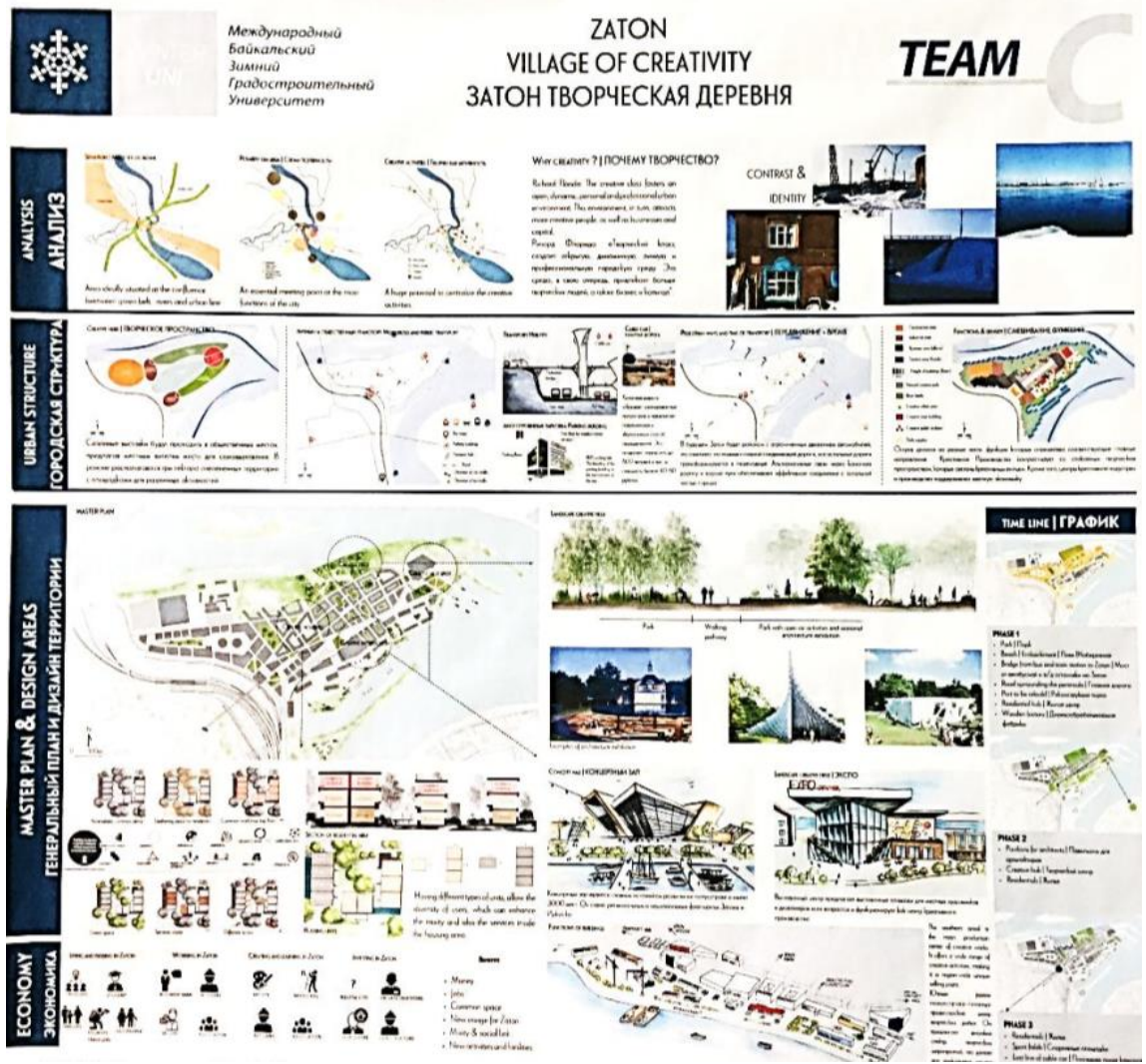

Fig. 3. Village of Creativity.

The CityLabZaton stands for the urban experiment - to create an urban environment where new types and modes of urban life could be tested. Aim of the project is to strenghten a more polycentric organisation of the city of Irkutsk which does not mean to decrease the importance of the historical center but to enhance the qualities of other districts by giving them more specific functions and identities. In this project new ways of housing, working and leisurement are presented. Student housing could be become a driving catalysator for developing the Zaton district in its experimental character but as well as for the improvement of connecting the area with the surroudning disctricts with their research and teaching institutions. However, the masterplan is not corresponding to the concept - more experimental typologies would habe been appreciated. 


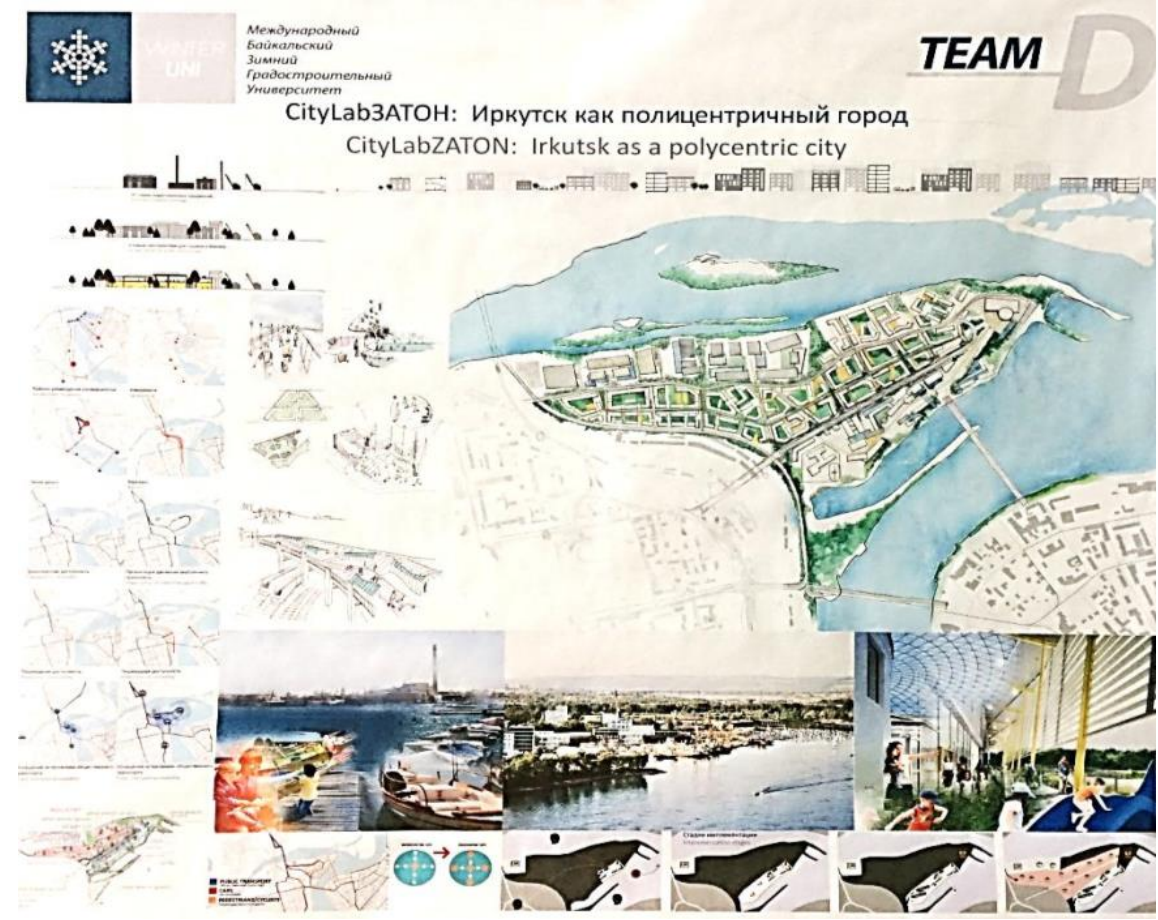

Fig. 4. CityLabZaton.

\section{Conclusion}

The projects, worked out during a 3-work-workshop are not at the level that they could be implemented right away - this was not the aim of the session. However, all four projects present valuable ideas, proposals which are worth to be worked out further. Taking very much the context into account, in its historical, cultural and social manner and by the same time implementing forward-looking ideas: this is the value that all projects have. By that the projects show new appoaches and future orientated understanding of urban planning in general that go far beyond the development of Zaton. I very much hope, that the city of Irkutsk takes the fresh impulses of the foreign (future) professionals and uses it for a sustainable future of Zaton.

\section{References}

1. R. Florida, The rise of the creative class (2012)

2. Chr. Reicher, Staedtebauliches Entwerfen (Wiesbaden, 2014)

3. Sh. Lontschakowa, R. Chotulew, Projekt planirowki zentralnoj tschasti goroda Irkutska (Irkutsk, 2012)

4. Welterbeliste der UNESCO (http://www.unesco.de/welterbeliste.html, 2018)

5. Y. V. Ragulina, A. V. Bogoviz, A. N. Alekseev, Advances in Intelligent Systems and Computing, 622, 568-573 (2018) 